\title{
Fulfilling Needs of Newly Enrolled Students: A Cultural Study of a Mobilized Guidance System
}

\author{
Firas Omar \\ Software Engineering Department, \\ Zarqa University, Jordan
}

\author{
Tareq Alhmiedat \\ Department of Information IT, \\ College of Computers and \\ Information Technology, Tabuk \\ University, Saudi Arabia
}

\author{
Ahmad Al-Qerem \\ Computer Science department, \\ Zarqa University, Jordan
}

\begin{abstract}
Mobile technology is becoming more popular around the world. The importance of such technology relates to its capability of allowing the user of performing many different Tasks simultaneously on daily basis. Nowadays, travelling from one place to another became easier than before. This is due to the availability of Electronic maps and guidance systems for different users. Despite the progress adding to the mobile application field, there are still some boundaries and limitations in using such devices. Some of the difficulties are connected directly to culture. Other difficulties are related to the lack of experience in using such technology and how far would a user trust such technology. In this research, light will be spotted on the idea of providing a guidance mobile application for the newly enrolled students to Zarqa University. Additionally, main restrictions and obstacles which limit the use of the mobile handset as a guide system will be taken into considerations. The research aim extends to studying the effect of cultural issues on the proposed system.
\end{abstract}

\section{Index terms}

Culture, HCI, Usability, Trust

\section{INTRODUCTION}

Day by day the need to computerize and simplify your life comes to take place in our life as a necessity. Many students around the world specially the newly enrolled ones, might possibly face hard time in knowing where to head to different places within the university. Therefore, it was our vision to develop and introduce a mobile application that would possibly help and support these students in their life and make the university a better place for them .to insure such beneficial outcome, the design and implementation of this smart mobile application has taken so many considerations in our account. Issues such as trust, culture and usability were considered through the process of design and implementation of the application

\section{RELATED WORKS}

The work presented in [1] includes a navigation system that relies on Bluetooth and Wi-Fi simultaneously. This kind of systems offers a number of advantages including: low cost, minimum hardware installation requirement, and the availability in most handheld devices. However, the navigation systems based on Bluetooth technology offers high localization error in the sum of ten meters.

The work presented in [2] includes web-based e-guide system for tourism using offloading and mobile integration. The designed system aims to help tourist accessing tourist information using smart devices. However, the proposed system does not offer any navigation facilities.

The advantage of the work presented in this paper offers an advantage of error high utilization in a precise number of three meters which give an advantage of other results comparing to the nature of the work.

\section{LITERATURE}

\subsection{Culture}

According to Hofstede, culture can be defined as "the collective programming of the mind which distinguishes the members of one group from people from another" [3]. Additionally, culture cannot be clearly understood by studying a single person or individual; it can only be dealt with as a set of shared characteristics within a group of people that affect the behaviours of individual members by providing rules for that group.

Additionally, culture combines itself on both the visible aspects of a group and a wide range of elusive aspects, including values, thoughts and behaviour. Culture can be conceptualized as a set of major variables that informs the responses of individuals in that culture to new practices, ideas and technologies, such as mobile data services.

One of the earliest definitions escribed culture as "That complex whole which includes knowledge, belief, art, morals, law, customs and any other capabilities and habits acquired by man" [4]. One of the most important definitions of culture was given by Kluckhohn, who declared that "Culture consists of patterned ways of thinking, feeling and reacting acquired and transmitted mainly by symbols consisting of the distinctive achievements of human groups including their embodiments in artefacts, the essential core of culture consists of traditional and historical derived and selected ideas and especially their attached values" [5]. Hofstede highlighted "Values" as the building bricks of any culture which are set early in childhood and shapes subjective definition of rationality. Hofstede added that values have both strength and direction, or alternatively they have a size and a sign [4].

Culture can be defined as a way of life, how people in a specific area or society learn how to dress, eat and communicate together. Particularly, it refers to socially learned and absorbed behaviours, beliefs and values that member of the same group or society share with others. It is absolutely a fact that different cultures exist in the world, each of which has its own cultural aspects and features, such as symbols and language, rules and values. 
Culture can be viewed as the number of attributes that people acquire from their childhood rearing. These attributes are fundamentally associated with their surroundings and environment that influence the responses of people in that culture to precede with the production of new ideas, use of new technology and practice it, taking into consideration that culture may affect the way people act and behave in general.

Because of the difficulty of the culture concept, Hofstede [4] developed conceptual models to represent the different dimensions through which culture can be understood. Cultural models tend to compare various cultures on a set of values. For example, Hofstede's model focuses on determining the patterns of thinking, acting and feeling.

\subsection{Cultural Dimensions: Hofstede Analysis:}

One of the most important compilations of national cultural characteristics was produced by Geert Hofstede [4]. Hofstede managed to build up an empirical-based study of cultural attributes by analysing data obtained from several surveys done between individuals in 53 countries between the years 1968-1972.

The survey questions were designed mainly to measure workrelated values. He used these measures of values, which are defined as components of culture, to identify national-level cultural characteristics common between all respondents. The analysis dimensions are:

\section{Individualism vs. Collectivism:}

Individualism is known for its loose social boundaries and frameworks whereby people are expected to take care of themselves and their own interests. Conversely, collectivism is known for its well established and tight social boundaries and frameworks wherein people look out for their welfare and where personal goals comes second place to those of the group [6].

Like the uncertainty-avoidance dimension, this dimension might have important behavioural implications for the use of mobile data services; users from individualist cultures tend to select services based on personal appropriateness. Such users choose mobile data services that are more personalized. Meanwhile, people with a collectivist tendency may be likely to use services that enable them to feel more connected to other people. Also, because highly individualistic cultures emphasize personalized goals, users from such cultures may prefer a mobile data services interface they can customize [6].

\section{Power Distance}

According to the theory of power distance theory, it is known that less powerful members of a society accept the unequal distribution of power. The main two poles of this dimension are high and low power distance.

Aspects of inequality could be found in many forms, such as physical or mental abilities or characteristics, social status and prestige, power, law and wealth. A good example of a high power distance culture is Jordan. The UK is an example of a low power distance culture.

Some of the well observed consequences related to the high power distance culture are obedience of people to authority, represented in certain figures such as boss, parent, religious figures, and officials who address others in a language filled with power and authority. On the opposite side, equality is the main common characteristic of low power distance cultures; in other words, people are considered to be equal, and there is no one who is regarded as intrinsically better than others.

\section{Masculinity vs. Femininity}

Masculine societies are typically characterised by some values such as the acquisition of wealth, ambition and differentiated gender roles. In such cultures, men are seen as assertive and they learn to be competitive and visible, stressing success and being job-oriented.

In such cultures, women are seen as growing and caring agents, with the emphasis on women's' fundamentally different role, which may lead to them avoiding certain types of jobs, such as taxi or bus driver.

On the other hand, in a feminine society, the dominant values for men and woman are development and caring behaviours. This society places less emphasis on assertiveness for both men and women, and the main goal or focus is on cooperation and sexual equality. According to Hofstede [4], a good example of masculine culture is Japan. Malaysia would be a good example of feminine culture.

\section{Uncertainty Avoidance}

Uncertainty avoidance can be defined as "the extent to which the members of a culture feel threatened by uncertainty and ambiguity along with their eagerness to avoid such situations" [4].

People in high uncertainty avoidance cultures view uncertainty as dangerous and show a low acceptance for risk. They tend to avoid uncertain situations by believing in absolute truths and knowledge, seeking stability and rejecting new or unusual ideas and behaviours. Conversely, people in low uncertainty-avoidance cultures deal well with ambiguity and can be classified as risk takers.

Uncertainty-avoidance possibly has a significant influence on behaviour related to the use of mobile data services. Users from a culture that tends toward uncertainty avoidance are more likely to avoid using mobile services when the quality of service is uncertain or uneven compared to that of traditional internet services [6]

\section{Long-Term vs. Short-Term Orientation:}

According to Hofstede [6], this dimension is based on a study was conducted by Michael Bond [7] in Hong Kong, which observed that Hofstede previous four cultural dimensions did not sufficiently reflect the Asian viewpoint on culture, but rather the latter was more related to the time orientation of Kluckhohn and Strodbeck [3].

According to Hofstede, the dimensions of both time and values are related to the future; "Long Term Orientation stands for the fostering of virtues oriented towards future rewards, in particular perseverance and economy". Its opposite pole is "Short Term Orientation" [4].

A good example of long-term culture is Pakistan. Short-term orientation stands for the fostering of virtues related to the past and present, in particular "respect for tradition, preservation of 'face' and fulfilling social obligations." A good example of short-term orientation culture is the UK.

\section{Trompennars Model Analysis}

Trompennars [8] developed a cultural model which has seven dimensions:

\section{Achievement vs. Ascription:}

This dimension describes how valuable and important is the status of the individual. Basically, at the achievement oriented 
cultures persons are valued and judged for what kind of achievement they completed in their lives.

It is found by Trompennars that in achievement oriented cultures, titles are only used in relevance to competency brought to the job. Usually, the respect for superior in hierarchy is based on how successfully the job is performed and how sufficient their knowledge [8].

As mentioned by Trompennars, the UK is classified as an example of the achievement oriented society. In ascription oriented societies, individuals derive their status from age, birth, gender or wealth. Also, respect for superior position in hierarchy is observed as an indication of the person commitment to the organization and its mission. Trompennars cited Argentina as a typical example of ascription oriented societies [8].

\section{Universalism vs. Particularism:}

Refers to the level in which an individual is committed to the set of standards and rules. Usually in universalistic cultures, the main focus is on rules while in particularistic cultures the focus is on relationships.

Normally in universalistic cultures, there is only one truth or reality, while in particularistic cultures there are number of perspectives on reality. Universalists treat all cases in the same way, while particularists treat cases according to their special qualities and create private understandings.

According to Trompennars, North Americans as well as 80\% of the Protestant countries are Universalists, while Brazil and the rest of Latin America are considered particularistic [8].

\section{Individualism vs. Communitarianism:}

Refers to the level of which the individual's priorities themselves over and ahead of the group needs. Usually, in individualistic cultures, authority might be the negotiator responsibility, while in the communitarian cultures; the negotiator is only a pass-on person who reports back to the group which approves the final decision.

In individualistic cultures, the decision maker normally accepts personal responsibility, while in communitarian communities it is always a joint responsibility standard.

Normally, individualists have the feeling that their achievements are mainly the results of their own hard work and effort, while communitarians believe that they achieve more as a group. According to the analysis of Trompennars, American people are considered to live in an individualistic culture, where individual freedom is prized more highly than the need to care for other individuals in the same society [8].

Based on the findings of Trompennars, French people are recognised as a part of the collectivistic culture, where the individualistic approach is not adopted in the society, and priority is given always to the group rather than to the individual [8].

\section{Neutral vs. Affective:}

Refers to the level in which persons of the society show or hold back their emotions and feelings. People in affective societies lean to reveal thoughts and feelings verbally and non-verbally. According to Trompennars, emotions flow easily and strongly without inhibition and physical contact, gesturing and strong facial expression are common in affective societies while in neutral societies people tend not to reveal what they are thinking or feeling physically [8].

According to Trompennars, Egypt belongs to the affective culture, with their meaningful emotions and feelings, while Japan is an example of neutral societies, with their sharp abilities to keep their feelings and expressions quiet and controlled [8].

\section{Diffuse vs. Specific:}

Refers to the level at which diffuse people get involved deeply with other people's life space, while specific people believe that relationships with others need to be explicitly defined and regulated, as if dealing with a contract.

Trompennars reported that Swedish culture is considered to be a specific culture, in which people tend to strictly separate work and personal life [8].

Diffuse oriented cultures are characterized by high degree of interpersonal relationships. In other words, people in such cultures engage with others in large areas of their private lives. Borders and barriers between personal life and work do not exist in a practical way. According to Trompennars, Nigeria is a standard example of diffuse oriented culture [8].

\section{Time Orientation:}

This dimension points to the time response of the culture. Moreover, it has two types: Monochronic (sequentially) and polychronic (synchronic) time.

Monochronic (sequentially) time is known and characterised by promptness, schedules and categorization or isolation of activities. Trompennars classified Sweden and many other north-west European countries as part of the sequential culture, where people perform only a single task at a time and stick to the schedule is a must [8].

According to Trompennars, in polychronic time culture, such as in India, people tend to engage with many things simultaneously, and emphasise the involvement of people. Even if there was a target or a final goal it might take several steps to accomplish it, especially when there are activities that are running in parallel [8]

\section{Internal vs. External Control:}

This dimension describes the attitudes of people on the subject of nature. According to Trompennars, internal control cultures instil certain beliefs that people can and must control nature by enforcing their strength on it. He described the UK as a typical example of internal control culture [8].

In external control countries such as Egypt, people believe in the external determinism of the environment, and submit to its laws, description and forces [8].

\subsection{Mobile Human-Computer Interaction}

The ACM defines human-computer interaction (HCI) as "a discipline concerned with the design, evaluation and implementation of interactive computing systems for human use and with the study of major phenomena surrounding them" [9].This definition positions mobile HCI as a sub-area focusing on one species of interactive computing systemsthe portable and handheld computer. The significant aspect of mobile HCI is user mobility. The user's agency for physical movement changes the conditions of interaction so profoundly that mobility is one of the key challenges for post-millennium research. 
Mobile prototypes are being developed in special application domains that tend not to refer to work done in the core of mobile HCI. The case of wireless application protocol (WAP) in Europe is a good example from the recent past. Academic research should not be a slave to the development of technology, but it should steer efforts across application domains.

Nonetheless, the first 10 years of mobile HCI research cannot be judged as being a failure. Mobile HCI has been, by and large, a technology-focused enterprise [9] and a model of fruitful industry-academia relationships. Numerous commercial products and services have been anticipated by academic publications and almost all major manufacturers and network operators have active research divisions that take part in academic conferences.

Location-based services, awareness, remote monitoring, media-capturing and sharing, browsers, online banking, business processes, games, office documents, voice communications, short messaging, email, and input interfaces are prime examples of research areas that have contributed to industry efforts. However, the bulk of this work has been local in a sense, specific to the application or setting, without generalizable understanding that carries over to new applications and settings. It is important to have stronger basic science without letting industry needs "off the hook."

The current research in this general area is breaking new ground by bringing into focus the expanding scope of mobile $\mathrm{HCI}$, from the user interfaces designed for the moving user to the immediate situations at hand, all the way to more advanced social and organizational cultures. In the end, the core of mobile HCI that links these scopes is how the users' actions will change their relation to their contexts, and how this in turn affects the use of computers. In other words, the unique aspect of mobile $\mathrm{HCI}$ is the strong influence of the environment, almost to the extent user could talk about human-environment-computer interaction [9].

Mobility is essentially about change, something transforming to something else as a consequence of a user's cycle of actions that provide new resources and place constraints for the resulting actions. Mobility is therefore both a limiting as an enabling factor.

Herein lays the greatest advantage of mobile technologies over stationary tools as a platform for HCI. They should not simply be conceived of as smaller or lower versions of desktop applications; they enable a host of new services that leverage their contexts for the benefit of the user. The environment is not only a condition for achieving something, but it can be actively exploited. The full spectrum of the conditions that are relevant spans the physiology of joint movement as well as to the sociology of human mobility.

Mobile HCI has been an active area for more than a decade, yet this research will be targeting not all of mobile HCI, but specifically the problems of user mobility and mobile use. The activities studied in HCI literature are illustrative of how mobile devices are becoming one of the most pervasive platforms for HCI. The diversity of frameworks needed to address mobility in these papers implies that researchers do not have a unifying framework for mobility, and may not have in the future. Instead, the phenomenon is tackled from multiple perspectives that are irreducible to each other.

The fluid and natural interactions enabled by modelling physics are common in games and are moving into mobile phones. Physics engines have been used in games for many years to make movements and interactions more realistic, or alternatively to be able to play with the laws to physics to create new game play. Mobile phones now have the processing power to do some of the same things in their interactions. Signs such as flicking pages to turn them or throwing a scrollbar and seeing it slow down the further it scrolls are easy for users to understand and make for playful and engaging interactions. Many phones now also join accelerometers so that the in the future the whole device could be used to gesture, for example tilting to zoom or scroll. Eslambolchilar and Murray-Smith suggest that techniques such as zooming and scrolling based on dynamic models for mobile phones are in their infancy, with many techniques hard-coded into applications, rather than using general models that could be applied across the whole interface. One reason for this is that many interaction designers are not familiar with the concepts, specification mechanisms and calibration tools needed to make these techniques work [9].

Until recently, most mobile devices used a small keyboard, or a touchscreen and stylus for input. Things are now changing with a new generation of devices based on touchscreens operated by fingers. The removal of the physical keyboard allows designers more flexibility to alter the size and shape of a device and to allow input on different parts of it, for example on the back, so that the screen is not obscured during input. However, it is not clear how effective users will be at interacting on devices such as these. It requires them to use fingers, thumbs or two hands together in different ways, sometimes on the front of the device and sometimes on the back. Wobbrock, Myers and Aung [9] presented three detailed studies characterising input using different hand positions on the front and back of the mobile phone devices to show the performance of these different surfaces. Their results show that the index finger is good for input on the front or back surface of the mobile device, while the thumb is usually preferred to be used on the back rather than front. However, the index finger has its limitations when complex motions are needed, wherein it performs better on the front of the device. These studies can help device designers understand how to create more effective interactions in future devices which may have very different form factors to the ones are currently used.

Fickas, Sohlberg and Hung [9] pointed that there has been a very fast growth in the use of in-car navigation devices over the past few years. The same is starting to happen in the area of pedestrian navigation, with many new mobile phones including GPS around us, receivers and mapping software. This has unlimited possibilities for all pedestrians, but there may be certain benefits for people with cognitive impairments. Cognitive impairments can affect navigation skills which are fundamental to personal independence, community integration and travel. The right technology could help overcome some of these problems. Due to their disability, cognitively impaired people's needs and requirements are different and standard navigation tools are not always suitable, particularly in the way that route following assistance is presented. Fickas, Sohlberg and Hung [9] studied a range of different presentation methods to discover the most effective way to provide route-following assistance for this user group. They studied the use of aerial maps, point of view maps, and audio and textual directions with a group of twenty cognitively impaired users.

Results showed that speech-based directions were the most effective, followed by text reminders. Speech was also given the highest preference rating by the study participants. The 
main reason for this is that it placed the lowest request on visual attention, a resource that was required in order to navigate their way through. The results of this work may also be beneficial to designers of general pedestrian navigation tools as route following can be cognitively demanding for everyone, and reducing the load on visual attention will allow all users to focus on the environment they are moving through.

Trains, buses, planes and taxis ought to be prime contexts of use for mobile devices. Using mobile devices while travelling is not only common; it is the selling point of business phones and PDAs. There is something in the "betweenness" of travelling that is easily seen as promising for mobile technologies. In their article entitled "Mobile technologies in mobile spaces: Findings from the context of train travel," Axtell, Hislop and Whittaker [34] investigated train travellers in the UK. Their argument was a strong empirical study revealing the physical, material, technological, social, and organizational problems of interaction while travelling. On the one hand, despite owning a good number of mobile devices, travellers are not able to do work anytime or anywhere they want. At times they have to limit their work to those tasks where communication is not necessary, and they may be forced to return to pens and papers to do the job. On the other hand, workers are not powerless in face of resource deprivations, but they exhibit quick-witted local adaptations to overcome restraints; and they plan themselves to address these limitations within a specific timeframe; in best cases they turn these limitations to their benefit. The broader point that Axtell, Hislop, and Whittaker [9] make is that users place not only to the restraints of their immediate surroundings; they adjust their practices to organizational expectations and norms. They conclude with a convincing critique of naive notions of "context"; even train travel is no clear-cut, unitary context of use, but users actively construct conditions for work by adapting local resources to their practices and their devices, yet they are continuously sensitive to non-present, non-visible demands.

In their article entitled "Organisational usability of mobile computing — volatility and control in mobile foreign-exchange trading", Sorensen and Al-Taitoon [9] expanded on the point that non-visible conditions shape the use of mobile technology. They traced the long-term evolution of technologies of foreign exchange trading from face-to-face bartering in the Babylonian civilization to the modern 24-hour on-floor and off-premises model, whereby traders orchestrate their use of phones, pagers and PDAs. Al-Taitoon and Sorensen [9] studied the traders of a Middle Eastern bank who used their mobile devices to make decisions in face of uncertainty and shifting risk. On the one hand, market volatility creates a need for off-premises trading and quick decision making under uncertainty, but on the other, this clashes with the need for organizational control. Mobile traders need special technical and social skills to manage with this problem. Al-Taitoon and Sorensen [9] presented evidence for the claim that what was understood as the usability of a mobile system depends critically on balancing individual and organizational control. Here, the strong role of mobile devices appears in the context of dynamically switching spheres of work and personal identities that demands looser coupling and more discretion.

Studies since the turn of the millennium [9] have repeatedly pointed out the importance of mobile phones in the coordination of interpersonal activities and (at a higher level) in the management of one's social networks. For many years now, Japan has been located at the lead of mobile services. Recently, the country has witnessed a massive jump from the use of pagers and SMS to mobile e-mail. In their article entitled "Kei-Tying teens: using mobile phone e-mail to bond, bridge, and break with social ties-a study of Japanese adolescents", Boase and Kobayashi [9] reported that Japanese youths not only established relationships with phones; they use phones to actively add new contact points to their networks. Japanese teenagers use mobile e-mail to bond and bridge with their friends, but not to break ties. These findings are exciting not only because they are telling of a recent expansion in the interpersonal uses of mobile phones, but also as they are telling of how mobile devices expand to the territory of social networking sites.

Boyd and Ellison [9] defined social networking sites as webbased services that "allow individuals to construct a public or semi-public profile within a bounded system, clear a list of other users with whom they share a connection, and finally view and traverse their list of connections and those made by others within the system". The findings of Boase and Kobayashi [34] bring about an attractive idea: that mobile email, although not designed for this purpose, can be and is being used for social networking activities. Instead of traversing digital connections, phones are chosen by users to "digitalize" connections that are created face-to-face. The authors report that meetings in halls and lobbies that are too brief for face-to-face conversations are opportunities to exchange e-mail addresses, and connection is maintained by sending messages throughout the day. E-mail messages reach recipients across device boundaries and help maintain connections, no matter whether one is on or off the desktop. The authors also report an association between the amount of bridging a user does and the strength of use: more bridging leads to more use of mobile phones. Mobile e-mail may be a sign of what may turn into Web 2.0 on mobile phones.

In their article "Theorizing mobility in community networks", Carroll and Rosson [9] analyzed the possibility of mobile technologies supporting community networks. Their target community was a rural town of 80,000 people located in the Appalachian Mountains with the purpose of facilitating information dissemination, discussion and collective activity. Their study was an exercise in and an extension of scenariobased analysis to the space of mobile services. Scenario-based analysis [10] has been one of the most powerful ideas in design-oriented HCI during the last decade.

The term "the conundrum of human-computer interaction" is explained by Carrol [10] thus: an imaginative person can entertain almost any form of interaction or interface, yet there are hard limits on the use of technology. A designer can assume a user who can type with two hands while walking, and a marketing researcher that train travellers are interested in killing time by watching advertisements on their devices. Carroll and Rosson [9] take the reader by the hand and lead them through a process to show how their framework lends itself to difficult phenomena like communities and mobility. The authors not only elaborate the notion of community for this purpose, but they draw from theoretical and empirical literature to build a scientific basis for their design choices. They developed principles for wireless community networks and discuss the special nature of mobility. The resulting scenarios show convincing ways of using the physical world and the proximity of community members. The article has a timely focus, since communities and more generally "social networking" is an important ingredient of the Web 2.0 movement. 
As a starting point for their article entitled "Storied Spaces: Cultural accounts of mobility, technology, and environmental knowing", Brewer and Dourish [9] referred to the sociologist John Urry [11], who suggested that mobility rather than society may be the primary animating metaphor for the present century. Brewer and Dourish [9] wrote that: "If mobility is culturally shaped, then it is a must to think about mobile technologies not so much as devices that help solve problems, but as sites at which social and cultural categories are enacted." By claiming that space is also a social product, they go beyond the argument, that what is called space can be understood from the perspective of geometry and experience. Technological representations of space are never devoid of perspective, but are always implicated in ways of movement and knowing the world. They argue that cultural logics feature in the collective understanding of space, and that technologies are not uncertain about conflicts between logics. Brewer and Dourish [9] developed this argument further through numerous examples whereby they re-interpreted contextaware services from new perspectives of cultural legibility, literacy and legitimacy.

\subsection{Trust in Mobility}

Over time, increased attention has been focused on the development process of trust in e-commerce. Trust became a serious topic for research because it is the cornerstone in creating satisfied and probable outcomes as a result of transactions which was also explained by Salam, Rao and Pegels [12], trust can be developed by the trustee to positively create a trustor. Such perception is important to reduce the uncertainty and risks of transaction that exist for the individuals willing to trust about a potential or existing relationship-business, social or otherwise [12].

\subsection{Usability:}

In the last few years, mobile devices reached a very popular place within the consumer lives that it became one of the very essential gadgets. Mobile device functionality has expanded from just a device to press and dial numbers to the form of personal digital assistants (PDAs) [13].

Currently, almost all mobile devices comprise a mobile phone, a calendar or memo, an alarm clock, an appointment schedule, a digital camera, an internet platform and many games. These functionalities were exclusively operating in PDAs before they became combined with mobile phones, during which time it became increasingly important to learn how to evaluate their use and the optimum ways to design mobile devices' functionalities.

Usability, which is related directly to mobile services that run on mobile devices, must be concerned with the mobile user and outlines of what interfaces for mobile services are appreciated and expected by the user.

Most traditional usability studies focused on the user of stationary devices, who can control the situation (that is the environment) in which it is to be used. Running traditional testing for mobile devices increases the risk for unrelated results due to failing to consider mobile characteristics. Therefore, in order to produce effective end-user programming in mobile devices, it is essential to create a new usability testing method based on consideration of mobile devices' characteristics [13].

Howarth et al.[14] defined the term usability as the effectiveness, efficiency, and satisfaction in which users of a certain application is capable of achieving precise goals ISO [14]. For many years, usability did not require justification in most quarters due to continuously growing awareness of its value, and software production organizations' investment in "doing usability", building privileged usability laboratories. This was achieved in many ways, such as buying usability equipment, conducting usability testing and training developers in usability engineering methods.

These investments have helped to make usability engineering an important part of the overall software development lifecycle. Accordingly, organizations want to maximize the effectiveness of their usability engineering processes. The literature, however, suggests that usability practitioners experience a number of difficulties that negatively impact the effectiveness of their work, which in turn impacts the effectiveness of the usability engineering processes within which they work.

According to Nielsen [15], usability is defined as the measure of the quality the user practices when interacting with something like a traditional software application, web site, or any other device the user can operate in some way. Usability is not something that could be applied on a surface to give it extra shine at the last minute; it is deeply affected by every decision in design and development. In order to achieve additional usability and user satisfaction, researchers must not consider a single component but deem multiple components that are related to users and the product. Therefore, by focussing on the user, authentic usability can be characterized by the following Nielsen [15]:

Learnability: The system must be easy to master, so users can rapidly start completing work with the system.

Efficiency: The system must be easy to remember, so when the user has effectively learned the system, a high level of productivity will be achievable.

Memorability: The system must be easy to remember, so that the casual user will able capable of returning to the system after some period of not having used it, with no need to learn everything from the start point.

Errors: The system must have a low error rate, so that users will be making a smaller number of errors during the use of the system. If they make errors, they can easily recover from them. In addition, terrible error possibilities must not happen.

Satisfaction: The system must be pleasing to use, so users are individually pleased during the time of usage.

In the case of a product, usability is decided by many factors such as the user's ease of use, user's perception of the quality of the product; the product's intuitiveness for the user; ease of learning and relearning, and the user's appreciation of the usefulness of the product Barnum [13].

In both users' and products' cases, usability must be planned by matching the use to a user, so that increasing the user's satisfaction of the product is the ultimate goal of applying usability. Therefore, useful usability in a computer system means that the application will provide the users with wellstructured computing environments. To achieve usability efficiently, a number of factors should be integrated:

1. Cognitive, perceptual, and motor capabilities and constraints of people in general.

2. Special and unique characteristics of the planned user population in particular.

3. Exclusive characteristics of the users' physical and social work environment. 
4. Exclusive characteristics and requirements of the users' tasks, which will be supported by the product.

5. Exclusive abilities and constraints of the selected software and or hardware and platform for the product.

Usability testing is the method of doing usability evaluation on the product development Lee and Grice [16]. Generally, the goal of usability testing is to find as many usability problems as possible during the test, afterwards, altering them before the product is released. Sometimes, the procedure for building usability testing ("usability engineering") starts with identifying a user, analysing tasks, and setting usability specifications (Lee and Grice [16].

It then passes through developing and testing prototypes and continues through repeated cycles of testing and development. Thus, the key goal of usability testing is to improve the usability of a product, and then, in the end, to increase the satisfaction of users.

\subsection{Familiarity}

Another way people subjectively lower uncertainty and simplify their relationships with others is familiarity. Familiarity is an understanding, often based on previous interactions, experiences, and learning of what, why, where and when others do what they do Beatty et al. [2]. By itself, familiarity and trust are distinctly different. Familiarity handles the understanding of the current actions of other people or of objects, while trust deals with opinions about the future actions of other people Flink and Schreiterer [18].

For example, familiarity with Amazon.com, one of the largest book selling internet vendors, would be the knowledge of how to search for books and information about them, and how to later order these books through the website interface. Familiarity in this context is a specific activity-based cognizance based on previous experience or learning of how to use the particular interface.

On the other hand, trust in Amazon.com, might involve providing credit card information based on the favourable belief (i.e. trust) that the information will not be wrongly used in any way in the future. Accordingly, familiarity and trust complement each other as complexity-reduction methods. Familiarity reduces uncertainty by establishing a solid reliable structure Flink and Schreiterer, [18]; trust reduces uncertainty by letting people hold "relatively reliable expectations" Flink and Schreiterer [18] about other people's favourable future actions Flink and Schreiterer, [18]. In the case of using Amazon.com, familiarity in its turn will reduce complexity through an understanding of how to search and buy books through the site and what the procedure involved.

Trust, on the other hand, would reduce other aspects of complexity by a priori ruling out unethical behaviour, such as misuse of credit card information. Trust and familiarity, however, are not of equal importance Flink and Schreiterer [18], because trust relates to the unknown future actions of others, and these are inherently more dynamic, general, complex, risky and less specific. In the case of Amazon.com, users' trust should be more important when buying books, Mp3s etc. than when enquiring about books, not only because the consequences of credit card misuse deal with the future, but also because the nature of potential credit card misuse is more complex and risky.

Despite the fact that familiarity and trust are different, they correlate to each other. The reason for this is that trust in another person or organization is built when the other person or organization behaves in accordance with one's own favourable expectations of them. Since these favourable behavioural expectations (trust) are naturally contextdependent, understanding the given context.

Familiarity is often an important antecedent Flink and Schreiterer [18]. Likewise, without familiarity with the context, it would be obvious that trust cannot be effectively attached to specific favourable behaviours and thus cannot be as strongly conferred. Familiarity creates this background "precondition for trust" Flink and Schreiterer [18]. Once again in the case of Amazon.com, people's familiarity with the concept of secure internet communications could enable them to entertain specific beliefs concerning the security measures they expect from the vendor (this is trust). Likewise, buyers who are not aware of spying on the internet (lack of familiarity) have no reason to hold such expectations (trust). Another reason that familiarity can build trust is that familiarity not only provides an outline for future expectations, but also lets people create solid ideas of what to expect based on previous interactions Cruz et al. [19].

In many cases, prior experience is the basis of trust (Perrons, 2009) and familiarity can both create trust, when the experience was favourable, and ruin trust, if experience is not favourable Flink and Schreiterer [2].. In the case of Amazon.com, people familiar with Amazon.com had probably previously bought from the site and in the process had likely noticed that the vendor behaved in accordance with what they expected such as respect of privacy, accurate charges to their credit card account, and sending updates on the status of their orders.

\section{PHASE TWO: QUESTIONNAIRE ANALYSIS}

Question One:

"I had visited the University website previously"

In this question, over $66 \%$ of the sample had agreed and strongly did. They explained that it is mandatory now a day to visit the web site of any intended or planned visit to any place prior to the visit. This will in its turn will fortify the visitor with knowledge of directions of how to get to the university which will lead in its turn to avoid being lost

In addition to the above reason, the agreed part of the sample mentioned that they might benefit from visiting the website in knowing what are the available courses and if there is any available discounts on selected courses.

On the other hand, slightly over $20 \%$ of the sample had chosen disagree and strongly disagree. They explained that they do not need to visit the university website for any reason. They added that they know how to get to the university location with no hassle to be mentioned.

It was noted that only $10 \%$ of the samples were neutral without giving a clear reason.

Question Two:

"It was hard to find the geographical location of the university when I visited it for the first time"

The majority of the sample disagreed and strongly disagreed on such statement. Around $73 \%$ of the sample explained that finding the location of the university was easy and didn't face any problems in doing such. 
This is explained by the fact the any student who would like to visit the university will be guided and given instructions of how to get to the university, these guidelines and instructions will in its turn achieve the goal of getting to the university with no hassle at all. By asking others, the participants achieved both uncertainty avoidance and collectivism theories by Geert Hofstede (2001).

On the other hand, less than $25 \%$ of the sample agreed and strongly did. They explained that they were visiting the university from an another city and travelling for more than 40 minutes to reach their destination, as a result, it would had been more easier if there was an application to help them in location where is the university and how to get to it.

Only one person had chosen neutral, she explained that the bus will take here from the city of Amman to Zarqa city without having to care about locating the university.

Question Three:

"Finding the registrar office was an easy thing to do"

$79 \%$ of the sample agreed and strongly did for such question. They explained that the registration building could be easily found near the entrance of the university which cause no problem for them from any sort. In addition, some of them explained that as soon as they entered the university the registration building is obvious in front of them.

On the other hand, $13 \%$ of the sample disagreed on such statement. They explained that finding the registration building is not an easy thing especially when arriving to the university by the bus because of the location of the bus station which is located at the very far end from the registration building.

Only one person had chosen neutral. He didn't give an explanation of his attitude.

Question Four:

"It wasn't easy to find the lecture halls around the university"

For this question, answers were varying. Around $66 \%$ of the sample had chosen agree and strongly agree, they explained that finding lecture halls across the different university building were difficult. They explained further that each building is located in a different location of the university which made it more difficult for them to find the lecture halls. They added that it would be useful to find some sort of guidance or a map that illustrates the locations of the lecture halls.

On the other hand, $28 \%$ of the sample had chosen disagree and strongly disagree. These participants had explained that it is part of the university life to search and face some hassle in finding the lecture halls within the entire university.

Only $6.9 \%$ of the sample was neutral. They explained that it would be better to have some sort of an application helping them locating the lecture halls. On the other hand, if there was no one then they had to live with the fact that they had to search over and over for the lecture halls.

Question five:

"Finding the Bus stop in the Zarqa University was easy"

Around $77 \%$ of the participants had agreed and strongly did for such question. They explained that the bus station was obvious for the visitors for two main reasons. Firstly, they arrived to the university by these buses and it is easy to follow were the buses are congregated in their station. Secondly, some of them explained that the buses are located at the very far end of the university and close to the second gate which could not be missed.

On the other hand, around $16 \%$ of the sample had chosen disagree and strongly disagree for such question. They explained that the bus stop station needs some directions to get to it. Besides that, they added that they more likely to be lost after spending some time at the university specially when visiting so many different buildings there for, it would be valuable to have any sort of guidance during their time at the university.

Only 3 participants $(7 \%)$ of the sample had chosen to be neutral. They explained that they are managing to get to the bus station with some sort of hassle. But, it would be better to have and sort of guidance to help them more and more.

Question Six:

"It was hard to find different facilities around the university"

For this question, around $20 \%$ of the sample had chosen agree. They explained that finding such facilities is not an easy thing to do. In addition, they added that it needs some time to find these facilities

On the other hand, around $63 \%$ of the sample had chosen disagree and strongly disagree. They explained that these facilities are available for everyone but depends on how far he/she is from them. They also added that by time and practice, students will know how to find such with no time to be mentioned.

Apart of the choices of agree or disagree, 7 participants (18\%) of the sample had chosen neutral. The explained that finding such facilities is not an important thing and they might need to use any of them once in each semester. They added sometime they do not visit such facilities because they don't know they are available for the students. Finally, they added that it would be a good idea to have some sort of guidance for them and they will defiantly start to use such facilities once they know to get to them.

Question Seven:

"Finding offices of the lecturers wasn't hard"

The majority of the sample had chosen to disagree with this question. Around $46 \%$ of the sample had refused such statement explaining that it is one of the most irritating thing in the university life is finding the offices of lecturers. They added that it might take up to a day to find a member of staff office which in its turn consumes loads of valuable time of students.

On the other hand, around $37 \%$ of the sample had chosen to agree on such statement. They explained that finding offices of lecturers in not a hard thing to do. They added that some offices are available within the school of each faculty and it doesn't need that much of hassle.

Neutrally, $14 \%$ of the sample explained that finding the offices of lecturers depends of prior knowledge about where are they are located. They also added that this process depends on which year the student is. The more years you spend in the university the more knowledge about offices location you'll gain. They commented that this would be very difficult for the new students.

Question eight: 
"It is not easy to head to different building in around the university"

For this question, around $70 \%$ of the sample disagreed on such statement. They explained that each building has a name and all building is obvious for each student. In addition, participants explained that some buildings are unique and cannot be missed.

On the other hand, $21 \%$ of the sample had chosen to agree on such statement. They explained that moving from one building to another in not an easy thing because some of the buildings look alike. They added that some buildings are located on the very far end of the university which needs some guidance to get there.

3 participants $7 \%$ had chosen neutral. They didn't give a clear explanation but they were mention that a guidance method will be appreciated.

\section{Question Nine:}

"Moving between two locations wasn't hard"

Around $56 \%$ of the sample had chosen to agree on such statement. They explained that the each building has its own name which will make it easy to calculate the distance between each of them. Additionally, they had mentioned that they could walk within each building to reach the other point and avoid walking under the direct sun light.

On the other hand, $23 \%$ of the participants of this study had chosen to disagree on such statement. They explained that finding the shortest path between two locations is extremely hard and not easy especially when being in such massive university with many buildings in different locations. They added that some time it might take up to 40 minutes to reach a location under the extreme hot sun which will defiantly develop some sort of burden on the students. They commented that finding shortest path between two locations might be easier for students who had spent more years in the university.

It was noticed that. $18 \%$ of the sample had chosen neutral. They explained that they didn't find any problem in walking between two locations in a shortest path between them. They added that because they had older friends they managed to learn how to find the shortest path between two locations. They added that finding a guidance to instruct them how to use shortest path between two locations would be highly appreciated specially among newly enrolled students.

\section{PHASE THREE: THE MOBILE APPLICATION}

The aim of this project was to investigate the issue with new enrolled students to the Zarqa University and the issue of being lost for many vital locations in the university such as admission, lectures halls and lecturers offices. By applying a survey to the new enrolled students, the statistics shown that around $80 \%$ of them faces serious problem in finding the designated locations.

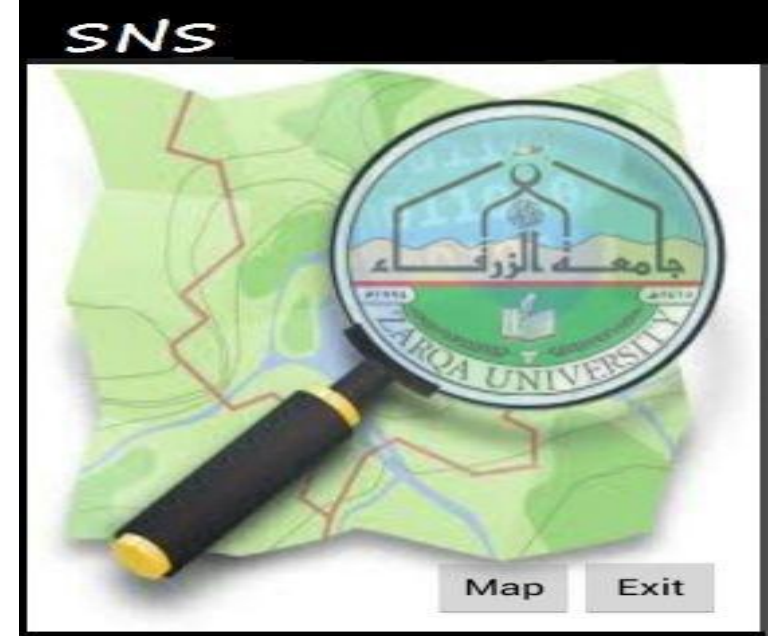

Figure1: First screen in the guidance application

As detailed previously, the system is very easy and straight forward to the user. This ease of use will support many HCI feature in order to insure that the user will find the system easy, enjoyable, and easy to remember. The figure below is the main screen of the application showing tall the areas of the university.

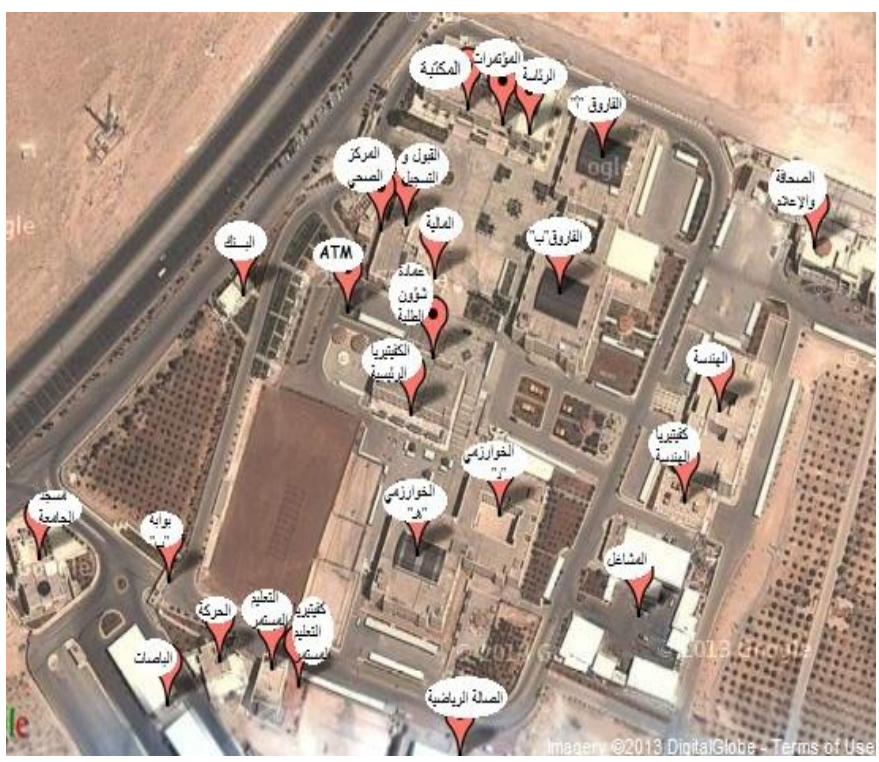

Figure.2: Second screen in the guidance application

\section{CONCLUSION}

From the results obtained for this study, it is obvious that developing a mobilized map application for smart phones would defiantly make the experience of newly enrolled students to the university much more exciting and encouraging for the ones that haven't enrolled yet. Such results had given an indication that the proposed application will defiantly solve several problems for the newly enrolled students. Many elements will be taken into considerations such as culture, trust and usability. The successful mixture of all of these elements will lead us to design and implement a suitable mobile application which in its turn fulfils the needs of newly enrolled students to Zarqa University. Such students in their turn will decided the success of such application or the failure of such. 


\section{ACKNOWLEDGMENT}

This research is funded by the Deanship of Research and Graduate Studies in Zarqa University /Jordan.

\section{REFERENCES}

[1] BARNUM, C.M. and DRAGGA, S., 2001. Usability testing and research. Allyn \& Bacon, Inc.

[2]BEATTY,P.,REAY,I.,DICK,S.andMILLER,J.,2011.Consu mertrustine-commercewebsites:ametastudy.ACMComputingSurveys(CSUR), 43(3),pp. 14.

[3] BOND, M.H .and HOFSTEDE, G., 1989.ThecashvalueofConfucianvalues.HumanSystemsM anagement, 8(3), pp.195-200.

[4]BUCHANAN,G.,FARRANT,S.,JONES,M.,THIMBLEBY, H.,MARSDEN,G.andPAZZANI,M., 2001. Improving mobile internet usability, Proceedings of the10th international conference onWorldWideWeb2001, ACM, pp.673-680.

[1] Agrawal, Rohit, and Ashesh Vasalya. "Bluetooth Navigation System using Wi-Fi Access Points." arXiv preprint arXiv: 1204.1748 (2012)

[2] Solaiman, H., and E. Abuelrub. "The Design of an Integrated Mobile e-Guide System for Tourism." International Journal of Interactive Mobile Technologies 4.2 (2010).

[3] Hofstede, G.2001.Culture'sConsequences: comparing values, behaviours, institutions, and organizations across nations (2ndEd.).Thousand Oaks, CA: SAGE Publications

[4] TYLOR, E.B., 1871. Primitive culture: researches into the development of mythology, philosophy, religion, art, and custom. John Murray.

[5] KLUCKHOHN, F.R. and STRODTBECK, F.L., 1951. Variations in value orientations

[6] Choi B, Lee I, Kim J, YunsukJ2005Aqualitativecross national study of cultural influences on mobile data service design. Conference on human factors in computing systems, CHI2005.ACMPress, New York, pp 661-670

[7] BOND, M.H and HOFSTEDE, G., 1989.ThecashvalueofConfucianvalues.HumanSystemsM anagement, 8(3), pp.195-200

[8] TROMPENAARS, F. and HAMPDEN-TURNER, C., 1998. Riding the waves of culture. N. Brealey Pub.

[9] PERRONS, R.K., 2009. The open kimono: How Intel balances trust and power to maintain platform leadership. Research Policy, 38(8), pp. 1300-1312.

[10] CARROLL, J.M., 2000.Makinguse: scenario-based design of human-computer interactions. The MIT press.

[11] Jones M, Marsden G. 2006 Mobile Interaction Design.UK: John Wiley \& sons.
[12] SALAMON, S.D.and D, ROBINSON, S.L., 2008. Trust that binds: The impact of collective felt Trust on organizational performance .Journal of Applied Psychology; Journal of Applied Psychology, 93(3), pp. 593.

[13] BARNUM, C.M. and DRAGGA, S., 2001. Usability testing and research. Allyn \& Bacon, Inc.

[14] Howart, J., Smith-Jackson, T, Hartson, R. 2009.Supporting novice usability practitioners with usability engineering tools. International journal of human computer studies, Vol67, issue 6.Pp533-549.

[15] JAKOB NIELSEN, 1993. Usability engineering. Morgan Kaufmann.

[16] Lee, K. B., Grice, R.A., 2004. Developing a reusability testing method for mobile devices. In: Proceedings o fthe International Professional Communication Conference, Piscataway, USA, 2004, pp.115-127.

[17]BEATTY,P.,REAY,I.,DICK,S.andMILLER,J.,2011.Cons umertrustinecommercewebsites:ametastudy.ACMCompu tingSurveys(CSUR), 43(3),pp. 14.

[18] FLINK, T. and SCHREITERER, U., 2010. Science diplomacy at the intersection of S\&T policies and foreign affairs: toward a typology of national approaches. Science and Public Policy, 37(9), pp. 665-677.

[19] CRUZ, C.C., GOMEZ-MEJIA, L.R. and BECERRA, M., 2010. Perceptions of benevolence and the design of agency contracts: CEO-TMT relationships in family firms. The Academy of Management Journal (AMJ), 53(1), pp. 69-89.

\section{AUTHOR'S PROFILE}

Dr. Firas Omar is an assistant professor in the software engineering department at Zarqa University, Jordan. He received his Ph.D. in information systems from Brunel University, London, UK, 2012.Hisresearchinterestmainlyconcernedin HCI beside cultural and usability studies. In addition, he is interested in the studies of trust and mobility.

Dr. Tareq Alhmiedat: is an Assistant professor in Computer Science Department at Zarqa University. He received aPh.D.in Computer Science from Loughborough University, Loughborough, UK, 2009.Hisresearchinterestsincludingtrackingmobiletargetsthroug hWirelessSensorNetworks, Robotic Systems, and Home automation and remote control application.

Dr. Ahmad al-Qerem obtained his $\mathrm{PhD}$ in mobile computing from Loughborough University, UK in 2008. He is interested in concurrency control for mobile computing environments, particularly transaction processing. He has published several papers in various areas of computer science. 